\title{
COMPATIBLE MAPPINGS AND COMMON FIXED POINTS (2)
}

\section{GERALD JUNGCK}

Department of Mathematics

Bradley University

Peoria, Illinois 61625

(Received November 17, 1986)

ABSTRACT. A common fixed point theorem of S.L. and S.P. Singh is generalized by weakening commutativity hypotheses and by increasing the number of functions involved.

KEY WORDS AND PHRASES. Common fixed points, commuting mappings, and compatible mappings.

1980 MATHEMATICS SUBJECT CLASSIFICATION CODE. $54 \mathrm{H} 25$

1. INTRODUCTION.

In [1] the concept of compatible mappings was introduced as a generalization of commuting maps $(f g=g f)$. The utility of compatibility in the context of fixed point theory was demonstrated by extending a theorem of Park and Bae [2]

The purpose of this note is to further emulate the compatible map concept. We extend the following strong result of S.L. Singh and S.P. Singh $|3|$ by employing compatible maps in lieu of commuting maps, and by using four functions as opposed to three.

THEOREM.1.1. Let $P, Q$, and $T$ be self maps of a complete metric space $(X, d)$ such that $P T=T P, Q T=T Q$, and $P(X) \cup Q(X) \subset T(X)$. If $T$ is continuous and there exists $r \in(0,1)$ such that $d(P x, Q y) \leq r \max \{d(T x, T y), d(P x, T x)$, $\left.d(Q y, T y), \frac{1}{2}(d(P x, T y)+d(Q y, T x))\right\}$ for all $x, y$ in $X$,

Then $P, Q$, and $T$ have a unique common fixed point.

2. PRELIMINARIES.

The following definition was given in [1].

Definition 2.1. Self maps $f$ and $g$ of a metric space $(x, d)$ are compatible iff $\lim _{n} d\left(f g x_{n}, g f x_{n}\right)=0$ whenever $\left\{x_{n}\right\}$ is a sequence in $x$ such that $\lim _{n} f x_{n}=\lim _{n} g x_{n}=t$ for some $t$ in $x$.

Thus, if $d(f g x, g f x) \rightarrow 0$ as $d(f x, g x) \rightarrow 0, f$ and $g$ are compatible. For example, suppose that $f x=x^{2}$ and $g x=2 x^{2}$ for $x$ in $R$, the set of reals. $f$ and $g$ are not commutative, but

$|f x-g x|=x^{2} \rightarrow 0$ iff $x \rightarrow 0$ and $|f g x-g f x|=2 x^{4} \rightarrow 0$ if $x \rightarrow 0$ so that $f$ and $g$ are compatible on $R$ with the usual metric. 
Now maps which commute are clearly compatible, but the converse is false. In fact, compatible maps need not be weakly commutative. Sessa [4] defined self maps $f$ and $g$ of a metric space $(X, d)$ to be a weakly commuting pair iff $d(g f x, f g x) \leq d(f x, g x)$ for $x$ in $x$. If $f$ and $g$ are weakly commutative they are obviously compatible, but the converse is false as the above example shows (e.g., let $x=1$.). See $[1]$ for other examples of compatible pairs which are not weakly commutative and hence not commuting pairs.

3. MAIN RESULTS.

LEMMA 3.1. Let $A, B, S$, and $T$ be self maps of a metric space $(X, d)$ such that $A(X) \subset T(X)$ and $B(X) \subset S(X)$, and let $x_{0} \in X$. If $r_{\varepsilon}(0,1)$ such that $d(A x, B y) \leq r \max (M x y)$ for $x, y \in X$ : where

$$
M x y=\left\{d(A x, S x), d(B y, T y), d(S x, T y), \frac{1}{2}(d(A x, T y)+d(B y, S x))\right\},
$$

then there is a Cauchy sequence $\left\{y_{n}\right\}$ in $x$ beginning at $x_{0}$ and defined by $y_{2 n-1}=T x_{2 n-1}=A x_{2 n-2}$ and $y_{2 n}=S x_{2 n}=B x_{2 n-1}$ for $n \in N$, the set of positive integers.

PROOF. Since $A(X) \subset T(X)$ and $B(X) \subset S(X)$, we can choose $x_{1}, x_{2}$ in $X$ such that $\mathrm{y}_{1}=\mathrm{Tx}_{1}=A \mathrm{x}_{0}$ and $\mathrm{y}_{2}=S \mathrm{x}_{2}=B \mathrm{x}_{1}$. In general, we can choose $x_{2 n-1}, x_{2 n}$ in $x$ such that

$$
y_{2 n-1}=T x_{2 n-1}=A x_{2 n-2} \text { and } y_{2 n}=S x_{2 n}=B x_{2 n-1}
$$

Thus the indicated sequence $\left\{y_{n}\right\}$ exists.

To see that $\left\{y_{n}\right\}$ is Cauchy, note that (3.1) and (3.2) imply that $d\left(T x_{2 n+1}, S x_{2 n+2}\right)=d\left(A x_{2 n}, B x_{2 n+1}\right) \leq r \max \left(M_{n}\right)$ where $M_{n}=\left\{d\left(A x_{2 n}, S x_{2 n}\right)\right.$, $\left.d\left(B x_{2 n+1}, T x_{2 n+1}\right), d\left(S x_{2 n}, T x_{2 n+1}\right), \frac{1}{2}\left(d\left(A x_{2 n}, T x_{2 n+1}\right)+d\left(B x_{2 n+1}, S x_{2 n}\right)\right)\right\}$. Then by (3.2) $M_{n}=\left\{d\left(T x_{2 n+1}, S x_{2 n}\right), d\left(S x_{2 n+2}, T x_{2 n+1}\right), \frac{1}{2} d\left(S x_{2 n+2}, S x_{2 n}\right)\right\}$. But $\frac{1}{2} d\left(S x_{2 n+2}, S_{2 n}\right) \leq \frac{1}{2}\left(d\left(S x_{2 n+2}, T x_{2 n+1}\right)+d\left(T x_{2 n+1}, S x_{2 n}\right)\right) \leq \max \left\{d\left(S x_{2 n+2}, T x_{2 n+1)}\right.\right.$, $\left.d\left(T x_{2 n+1}, S x_{2 n}\right)\right\}$ since the larger of two numbers is greater or equal to their average. So we have $\max \left(M_{n}\right)=\max \left\{d\left(S x_{2 n+2}, T x_{2 n+1}\right), d\left(T x_{2 n+1}, S x_{2 n}\right)\right\}$ with $d\left(T x_{2 n+1}, S x_{2 n+2}\right) \leq r \max \left(M_{n}\right)$. But if $d\left(T x_{2 n+1}, S x_{2 n+2}\right) \leq r d\left(T x_{2 n+1}, S x_{2 n+2}\right)$, $d\left(T x_{2 n+1}, S x_{2 n+2}\right)=0$, since $r \in(0,1)$; thus $\max \left(M_{n}\right)=d\left(T x_{2 n+1}, S x_{2 n}\right)$ and we conclude $d\left(T x_{2 n+1}, S x_{2 n+2}\right) \leq r d\left(T x_{2 n+1}, S x_{2 n}\right)$.

Similarly, $d\left(T x_{2 n+3}, S x_{2 n+2}\right) \leq r d\left(S x_{2 n+2}, T x_{2 n+1}\right)$.

Consequently, (3.2) implies that $d\left(y_{m+1}, y_{m}\right) \leq r d\left(y_{m}, y_{m-1}\right)$ for $m$ even or odd. This last inequality implies that $\left\{y_{m}\right\}$ is Cauchy, as desired. I

We shall also need the following simple result from [1] (Proposition 2.2(2a)). 
PROPOSITION 3.1. If $f$ and $g$ are compatible self maps of a metric space $(x, d)$ and $\lim _{n} f x_{n}=\lim _{n} g x_{n}=t$ for some $t$ in $x$, then $\lim _{n} g f x_{n}=f t$ if $f$ is continuous.

We can now state and prove our generalization of Theorem 1.1.

THEOREM 3.1. Let $A, B, S$ and $T$ be self maps of a complete metric space $(X, d)$. Suppose that $S$ and $T$ are continuous, the pairs $A, S$ and $B, T$ are compatible, and that $A(X) \subset T(X)$ and $B(X) \subset S(X)$. If there exists $r \varepsilon(0,1)$ such that $d(A x, B y) \leq r \max (M x y)$ for $x, y$ in $X$, where

$$
M x y=\left\{d(A x, S x), d(B y, T y), d(S x, T y), \frac{1}{2}(d(A x, T y)+d(B y, S x))\right\}
$$

then there is a unique point $z$ in $x$ such that $z=A z=B z=S z=T z$.

PROOF. By the Lemma 3.1. there is a sequence $\left\{x_{n}\right\}$ in $x$ such that $S x_{2 n}=B x_{2 n-1}=y_{2 n}, T x_{2 n-1}=A x_{2 n-2}=y_{2 n-1}$, and such that the sequence $\left\{y_{m}\right\}$ is Cauchy. Since $(x, d)$ is complete $\left\{y_{m}\right\}$ converges to a point $z$ in $X$. Consequentily, the subsequences

$$
\left\{A x_{2 n}\right\},\left\{S x_{2 n}\right\},\left\{T_{2 n-1}\right\},\left\{B x_{2 n-1}\right\} \text { converge to } z \text {. }
$$

Since $A$ and $S$ are compatible and $B$ and $T$ are compatible, the continuity of $S$ and $T,(3.4)$, and Proposition 3.1. imply

$$
\mathrm{TTx}_{2 n-1}, \mathrm{BTx}_{2 n-1} \rightarrow \mathrm{Tz} \text { and } \mathrm{SSx}_{2 n}, \mathrm{ASx}_{2 n} \rightarrow \mathrm{Sz} \text {. }
$$

Then (3.3) implies $d(S z, T z)=1 \lim _{n} d\left(A S x_{2 n}, B T x_{2 n-1}\right) \leq r \max \left(1 \mathrm{imM}_{n}\right)$ where $M_{n}=\left\{d\left(A_{2 n} x_{2 n}, S S x_{2 n}\right), d\left(B T x_{2 n-1}, T T x_{2 n-1}\right), d\left(S S x_{2 n}, T T x_{2 n-1}\right), \frac{1}{2}\left(d\left(A S x_{2 n}, T T x_{2 n-1}\right)+\right.\right.$ $\left.\left.d\left(S S x_{2 n}, B T x_{2 n-1}\right)\right)\right\}$. By (3.5), $\quad \lim _{n} M_{n}=\left\{0,0, d(S z, T z), \frac{1}{2}(d(S z, T z)+\right.$ $d(S z, T z))\}$, so that $d(S z, T z) \leq r d(S z, T z)$. Since $0<r<1$, $S z=T z$.

Also, $d(A z, T z)=\lim _{n} d\left(A z, B T x_{2 n-1}\right) \leq r \max \left(\lim _{n} M_{n}\right)$ where $M_{n}=\{d(A z, S z)$, $\left.d\left(B T x_{2 n-1}, T T x_{2 n-1}\right), d\left(S z, T T x_{2 n-1}\right), \frac{1}{2}\left(d\left(S z, B T x_{2 n-1}\right)+d\left(A z, T T x_{2 n-1}\right)\right)\right\}$. Since $S z=T z$, (3.5) yields: $\lim _{n} M_{n}=\left\{d(A z, T z), 0,0, \frac{1}{2}(d(A z, T z))\right\}$; therefore, $d(A z, T z) \leq r d(A z, T z)$ from which (as above) we infer $A z=T z(=S z)$. But if we use this last stated equality in (3.3) with $x=y=z$, we obtain:

$A z=B z=S z=T z$.

In fact, $z$ is a common fixed point of $A, B, S$, and $T$. For (3.3) and (3.4) yield: $d(z, B z)=\lim _{n} d\left(A x_{2 n}, B z\right) \leq r \max \left(\lim _{n} M_{n}\right)$ with $M_{n}=\left\{d\left(A x_{2 n}, S x_{2 n}\right), d(B z, T z), d\left(S x_{2 n}, T z\right), \frac{1}{2}\left(d\left(A x_{2 n}, T z\right)+d\left(B z, S x_{2 n}\right)\right)\right\}$. Then $\lim _{n} M_{n}=\left\{0,0, d(z, T z), \frac{1}{2}(d(z, B z)+d(B z, z))\right\}$ by (3.4) and (3.6). We thus 
obtain $d(z, B z)=r d(z, B z)$, and we conclude that $z=B z=A z=S z=T z$.

That $z$ is the only common fixed point of $A, B, S$, and $T$ follows easily from (3.3)./

We conclude with an example of four functions which satisfy the hypothesis of Theorem 3.1., no three of which satisfy the hypothesis of Theorem 1.1..

EXAMPLE 3.1. Let $x=[1, \infty)$ and $d(x, y)=|x-y|$ for $x, y \in X$. Define $A x=x^{3}, B x=x^{2}, S x=2 x^{6}-1$ and $T x=2 x^{4}-1$ for $x$ in $x$. The functions are al1 continuous and satisfy $A(X)=B(X)=S(X)=T(X)=X$. Moreover, $|S x-A x|=\left|2 x^{2}+1\right|\left|x^{2}-1\right| \rightarrow 0$ iff $x \rightarrow 1$ since $x \geq 1$, and $|A S x-S A x|=$ $6 x^{6}\left(x^{6}-1\right)^{2} \rightarrow 0$ iff $x \rightarrow 1$ since $x \geq 1$. Thus, $d(A x, S z) \rightarrow 0$ only if $x \rightarrow 1$, in which instance $d(A S x, S a x) \rightarrow 0$. So $A$ and $S$ are compatible; but they are not a weakly commuting and hence not a commuting pair (Let $x=2$ ). Similarly, $T$ and $B$ are compatible, since $|T x-B x|=\left(2 x^{2}+1\right)\left|x^{2}-1\right|+0$ iff $x \rightarrow 1$ $(x \geq 1)$ and $|T B x-B T x|=2\left(x^{4}-1\right)^{2} \rightarrow 0$ iff $x \rightarrow 1(x \geq 1)$. Finally, $|S x-T y|=2\left|x^{3}-y^{2}\right|\left|x^{3}+y^{2}\right| \geq 2|A x-B y| 2$ for $x, y \geq 1$; therefore, $|A x-B y| \leq \frac{1}{4}|S x-T y| \leq \frac{1}{4} \max (M x y)$ for $x, y$ in $x$. Hence (3.3), and thus the hypothesis of Theorem 3.1., is satisfied. Observe also that no one of $A, B, S$, or $T$ commutes with any two of the remaining three functions.

of course, common fixed point theorems other than Theorem 1.1 follow from Theorem 3.1.. See, for example, Corollary 3.2 of $|1|$ which in turn has Theorem 1. of $[5]$ as a corollary.

\section{REFERENCES}

1. Jungck, G. Compatible mappings and common fixed points Internat. ‥ Math. Math. Sci. 9 (1936)

2. Park, S. and Bae, Jong Sook Extensions of a fixed point theorem of Meir and Keeler. Ark. Mat. 19(1981) 223-228

3. Singh, S.L. and Singh, S.P. A fixed point theorem. Indian J. Pure Appl. Math. 11(1980) 1584-1586.

4. Sessa, S. On a weak commutativity condition in fixed point considerations, Publ. Inst. Math. 32(46)(1982) 149-153.

5. Hadzic, 0lga Common fixed point theorems for family of mapings in complete metric spaces. Math. Japonica 29(1984) 127-134. 


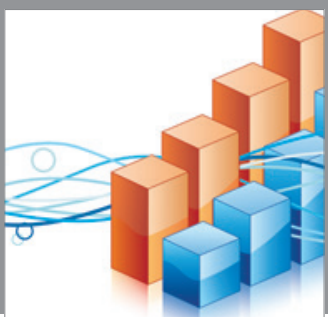

Advances in

Operations Research

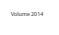

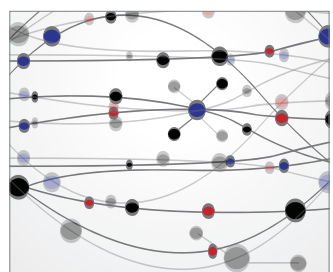

\section{The Scientific} World Journal
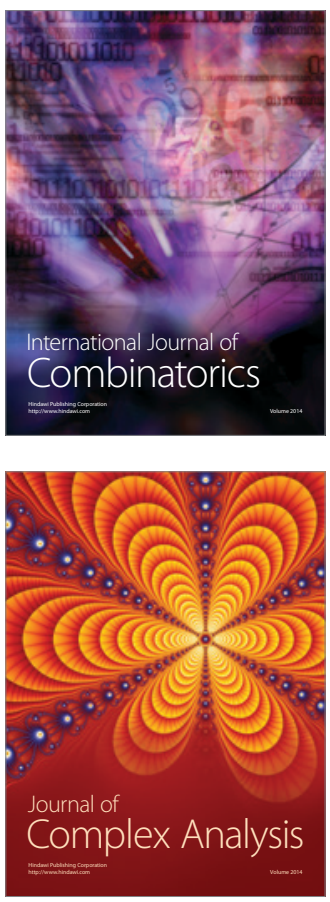

International Journal of

Mathematics and

Mathematical

Sciences
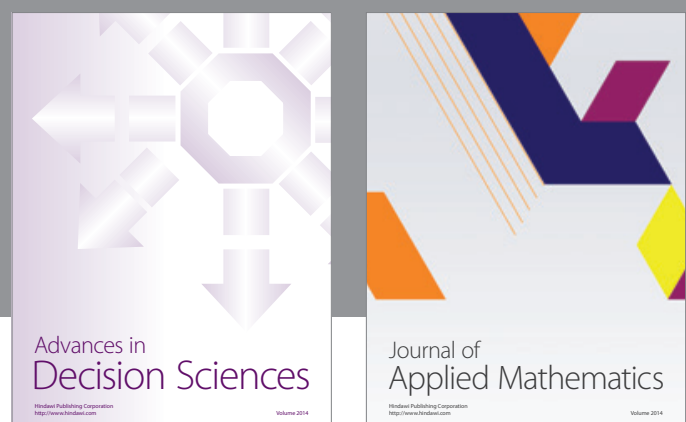

Journal of

Applied Mathematics
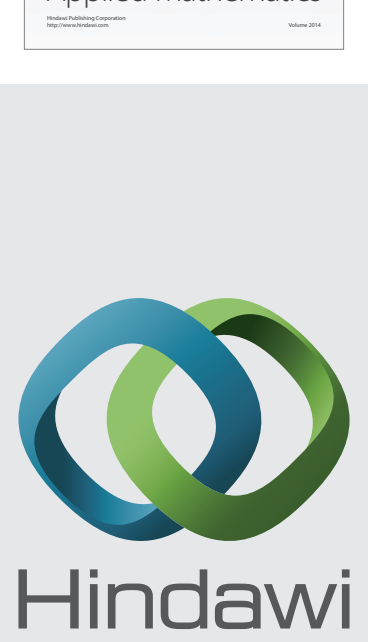

Submit your manuscripts at http://www.hindawi.com
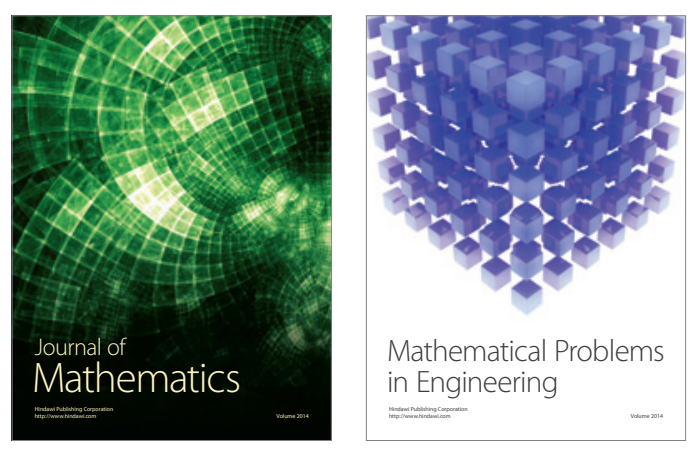

Mathematical Problems in Engineering
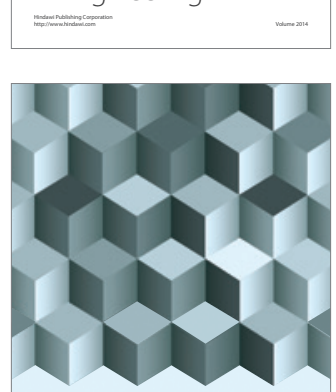

Journal of

Function Spaces
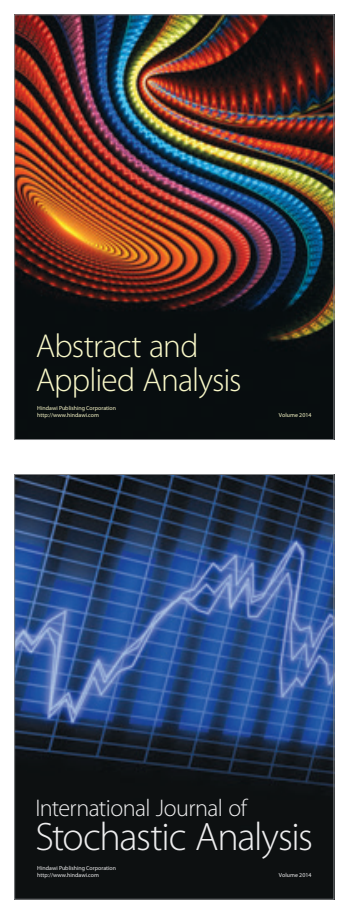

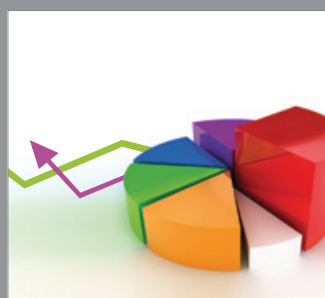

ournal of

Probability and Statistics

Promensencen
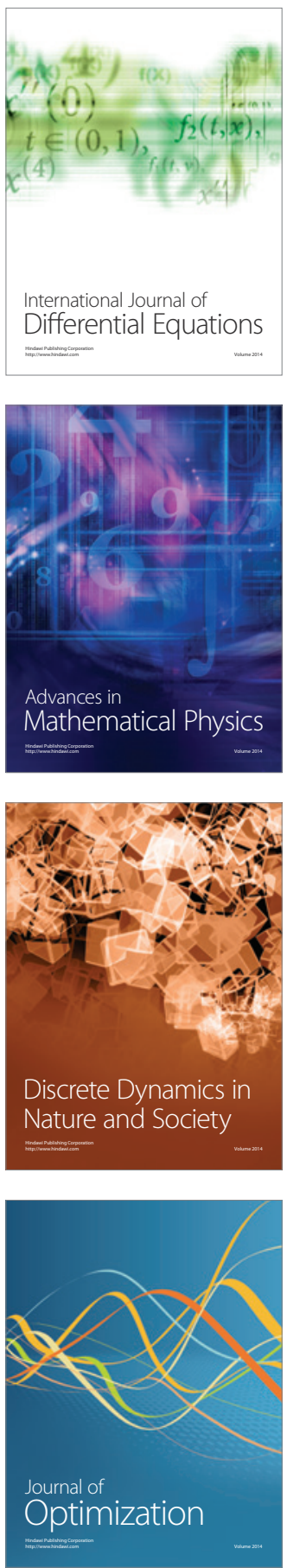